\title{
Molecular epidemiology of Panton- Valentine Leukocidin-positive community-acquired methicillin resistant Staphylococcus aureus isolates in pastoral communities of rural south western Uganda
}

\author{
Benon B. Asiimwe ${ }^{1,2,3^{*}}$, Rossella Baldan ${ }^{1}$, Alberto Trovato ${ }^{1}$ and Daniela M. Cirillo ${ }^{1,2}$
}

\begin{abstract}
Background: The emergence of multidrug resistant Staphylococcus aureus strains, including methicillin resistant (MRSA), is a global concern. Treatment of bacterial infections in Uganda's health care settings is largely empirical, rarely accompanied by laboratory confirmation. Here we show the burden, characteristics of MRSA and epidemiology of Panton-Valentine Leukocidin (PVL) positive strains in asymptomatic carriers in pastoral households of south-west Uganda.

Methods: Nasal swabs from 253 participants were cultured following standard methodology. MRSA strains were identified by detection of the mecA gene and SCCmec typing, and PVL genes detected by PCR. Pulsed Field Gel Electrophoresis (PFGE) was done to evaluate possible transmission patterns. Spa typing of PVL positive isolates was done to study the epidemiology of virulent strains in this setting.

Results: S. aureus was isolated in 29\% $(n=73)$ of the participants, of which 48 were MRSA by mecA typing. PVL-encoding genes were found in $49.3 \%(n=36)$ of the 73 isolates, of which 25 were also mecA positive. Among the PVL negative strains $(n=37), 62.2 \%(n=23)$ carried the mecA gene. The most common SCCmec type was V, detected in 39 (18 PVL positive and 21 PVL negative) isolates. PFGE clustered 21/36 (58.3\%) PVL positive isolates divided in four pulsotypes and 18/37 (48.6\%) PVL negative isolates divided in eight pulsotypes. The most prevalent Spa types were t318 $(26.5 \%, n=9)$ and t645 $(20.6 \%, n=7)$; while other common Spa types were t11656 $(n=3), \mathrm{t} 127(n=3)$ and $\mathrm{t} 355(n=3)$.
\end{abstract}

Conclusion: The study shows a high prevalence of community acquired (CA)-MRSA, and PVL-positive isolates with two predominant spa types in rural Uganda, further complicating infection control strategies in these underprivileged communities.

\footnotetext{
* Correspondence: basiimwe@chs.mak.ac.ug

${ }^{1}$ Emerging Bacterial Pathogens Unit, IRCCS San Raffaele Scientific Institute,

Via Olgettina 58, Milano, Italy

${ }^{2}$ Universita Vita-Salute San Raffaele, Via Olgettina 58, Milano, Italy

Full list of author information is available at the end of the article
} 


\section{Background}

About a third of healthy individuals in the community are asymptomatically colonized with Staphylococcus aures (S. aureus) in the nostrils [1], a very important finding considering the fact that nasal carriage of $S$. aureus has been associated with subsequent infection [2], and carriers are an important source of spread of infection in communities. A major concern is the world-wide emergence of methicillin resistant $S$. aureus (MRSA) in the community [3]. In contrast with health care associated MRSA (HA-MRSA) infections, community associated MRSA (CA-MRSA) infections can occur in healthy individuals [4], suggesting that these strains have greater virulence. Skin and soft-tissue infections represent about 90\% of cases of CA-MRSA infection, mostly characterized by abscesses or cellulitis with purulent drainage [3].

A predominant feature of CA-MRSA is the presence of the Panton-Valentine Leukocidin $(P V L)$ genes that encode a $S$. aureus exotoxin that induces lysis of monocytes and neutrophil granulocytes [5]. Additionally, there is evidence that PVL-positive $S$. aureus strains susceptible to methicillin (MSSA) may be reservoirs for the development of PVL-positive MRSA via the integration of the staphylococcal cassette chromosome mec (SCCmec) elements including the mecA gene conferring methicillin resistance [6]. Another key feature of CA-MRSA is that the strains mainly harbor SCCmec types IV and V [7-9], and a relationship between CA-MRSA, SCCmec type IV and V and PVL has been confirmed in some studies $[10,11]$.

While efforts have been made to map out the geographical predominance and spread of different CAMRSA clones worldwide [3], little is known about its magnitude and genetic composition in developing countries, especially in Africa. Molecular analytical techniques such as pulsed field gel electrophoresis (PFGE), multilocus sequence typing (MLST), spa and SCCmec typing have been used to show both the spread and evolution of MRSA. PFGE is still considered the gold standard for typing MRSA isolates, and is one of the most discriminative typing methods [12]. While MLST is an excellent tool for investigating clonal evolution of MRSA, it is rather expensive, labour intensive and time consuming. Sequences from the polymorphic region of the $S$. aureus protein A (spa) gene have been used to develop a singlelocus sequence typing technique for MRSA [13] with a discriminatory power between PFGE and MLST, and ability to investigate both molecular evolution and outbreak situations [14], while remaining simple.

The resistance of $S$. aureus to methicillin is caused by the mecA gene, located on a mobile genetic element, the staphylococcal cassette chromosome mec (SCCmec) [7]. Currently, eleven main SCCmec types (I to XI) are known [15], and Zhang et al. developed a multiplex PCR for the characterization of SCCmec type I to V [16].
In African countries, CA-MRSA has been reported in a few studies in Mali [17], Nigeria [18], Algeria [19], Egypt [20] and Gabon [21]. In Uganda, a few studies have been done at tertiary health care centers [22-25], and these have focused on HA-MRSA. Community studies have focused on $S$. aureus carriage in raw milk and its products as well as in urban milk vendors [26, 27]. We set out to establish the prevalence and molecular epidemiology of $P V L$-positive CA-MRSA isolates from pastoral communities of rural south-western Uganda so as to inform public health on how to develop effective strategies to prevent spread MRSA in these and surrounding communities.

\section{Methods}

\section{Study area}

The study was carried out in rural pastoral households of Kiruhura district, South Western Uganda. The area is a rangeland, populated by agro-pastoralists and seasonally itinerant semi-nomads whose livelihoods mainly depend on consumption and trade of cattle and their products; and small subsistent crop farming.

\section{Study design and sampling}

A cross-sectional study of $S$. aureus carriage in the area was conducted as part of a zoonotic diseases study among pastoral communities of Kiruhura district, South Western Uganda, in 2013. A total of 196 homesteads from two sub-counties (100 from Kanyaryeru and 96 from Sanga) were recruited and sampled. The subcounties were purposively selected by the zoonoses study because they bordered Lake Mburo National Park, with a porous human-animal interface. All participants did not have a history of recent hospitalization, and the only demographics characteristics recorded were sex and selfreported age. In each household, only a nasal swab was taken for any participant and these were inoculated into Brain-Heart Infusion (BHI) broth in $15 \mathrm{ml}$ propylene tubes and stored on ice before same day transportation to the Department of Microbiology at Mbarara University of Science and Technology for culture.

\section{Sample culture, isolation and identification}

Initial bacterial culture and isolation was done according to methods described by Cheesbrough [28], with minor modifications. Briefly, $50 \mu \mathrm{l}$ of culture broth was inoculated on $5 \%$ sheep blood agar medium and incubated for $18-20 \mathrm{~h}$ at $37^{\circ} \mathrm{C}$. Preliminary identification of the bacteria was carried out based on colony characteristics such as shape, size, color and hemolysis patterns. Isolates suspected of being $S$. aureus were shipped in BHI with 20\% glycerol to the Emerging Bacterial Pathogens Unit (EBPU) at San Raffaele Scientific Institute in Milan, Italy, for identification and molecular characterization. At the EBPU, all isolates were sub-cultured on mannitol 
salt agar (Oxoid Ltd, Hampshire, England), then on blood agar (Becton Dickinson, Heidelberg, Germany), and subjected to the tube coagulase test in rabbit plasma with EDTA (Remel, KS, USA). MRSA strains were identified by detection of the mecA gene and SCCmec typing.

DNA extraction, SCCmec typing and PVL genes detection Bacterial DNA was prepared from isolated colonies suspended in $500 \mu \mathrm{l}$ Triton X-100 lysis buffer with $1 \%$ Triton and $20 \mu \mathrm{l}$ of $1 \mathrm{mg} / \mathrm{ml}$ lysostaphin, incubated at $37^{\circ} \mathrm{C}$ for $1 \mathrm{~h}$, followed by phenol-chloroform extraction. SCCmec typing was done by multiplex PCR using primers and protocols for SCCmec types and subtypes I, II, III, IVa, IVb, IVc, IVd, and V and the mecA gene according to Zhang et al. [16]. The MRSA strain COL (SCCmec type I, mec gene complex B and $c c r$ gene complex 1) was used as positive control. Additionally, amplification of the Panton - Valentine Leucocidin $(P V L)$ toxin genes, lukS$P V$ and $l u k F-P V$, was performed using the $S$. aureus strain ATCC49775 as positive control, and primers and protocols as described by Lina et al. [29].

\section{Genotyping of isolates}

All isolates were subjected to molecular epidemiological analysis by PFGE after SmaI digestion using the CHEF Genomic DNA Plug kit (Bio-Rad) according to a standardized protocol [30]. PFGE was run using a CHEF DRIII system (Bio-Rad). The InfoQuest FP (v5.1) software (Bio-Rad Laboratories) was used to analyze PFGE profiles, according to interpretation criteria described by Tenover et al. [12]. Clustering analysis was achieved using Dice similarity coefficients and the unweighted pair group method with averages (UPGMA) at 1.5\% optimization and $1.5 \%$ position tolerance. PVL-positive strains were further subjected to spa-typing according to Frenay et al. [13]; and spa types were assigned on the Ridom SpaServer (http://spaserver.ridom.de) curated by the SeqNet.org initiative [31].

\section{Results}

Socio-demographic characteristics and S. aureus carriage

The study sampled 196 households, and nasal swabs were taken from 253 participants (172 males and 81 females) with average age of 14 years and a range of 6 to 48 years. Of the samples, 132 (52.2\%) were Staphylococcus spp, of which only 73 were S. aureus (carriage rate of $29 \%$ ) and further characterized. The 73 isolates were obtained from 48 (65.7\%) males and 25 (34.3\%) females. The average age of the 73 participants whose isolates were characterized was 13, with a range of 6 to 45 years.

\section{Prevalence of PVL and mecA genes}

PVL-encoding genes were found in $49.3 \%(n=36)$ of the $73 \mathrm{~S}$. aureus isolates, while mecA was detected in
$65.8 \%(n=48)$ of the 73 isolates. The proportion of PVL positive isolates carrying the mecA gene was $25 / 36$ (69.4\%) (Table 1), while $23 / 37(62.2 \%)$ of the isolates without the PVL gene possessed the mecA (Table 2). Among the PVL positive isolates, 18 of the $25 \mathrm{mec} A$

Table 1 PFGE profiles, Spa types, mecA, and SCCmec types of $P V L$ positive isolates

\begin{tabular}{|c|c|c|c|c|}
\hline Isolate ID & Pulsotype & Spa type & mecA & sccmec \\
\hline T095Na & $\mathrm{A} 1$ & NT & + & V \\
\hline $\mathrm{T} 101 \mathrm{Na}$ & $\mathrm{A} 1$ & NT & + & IVC \\
\hline T047Na & A1 & $\mathrm{t} 127$ & + & IVC \\
\hline T070Na & A1 & $\mathrm{t} 127$ & + & IVC \\
\hline T056N & A2 & t318 & - & - \\
\hline T099Nd & A3 & t2393 & + & IVC \\
\hline $\mathrm{T} 149 \mathrm{Na}$ & A4 & t645 & + & IVC \\
\hline $\mathrm{T} 101 \mathrm{Ng}$ & A5 & t318 & + & V \\
\hline T005Na & B1 & t318 & + & V \\
\hline T021 Nb & B1 & t318 & + & V \\
\hline T021NC & B1 & t318 & + & V \\
\hline T097Na & B1 & t318 & + & V \\
\hline $\mathrm{T} 125 \mathrm{Na}$ & B1 & t318 & + & V \\
\hline T141Nc & B1 & t318 & + & V \\
\hline T047Nd & B1 & t186 & + & V \\
\hline $\mathrm{T156N}$ & B1 & t186 & + & V \\
\hline T019N & B2 & $\mathrm{t} 186$ & + & V \\
\hline $\mathrm{T} 119 \mathrm{Nb}$ & C1 & t355 & + & V \\
\hline $\mathrm{T} 135 \mathrm{Na}$ & C2 & t729 & - & - \\
\hline $\mathrm{T} 132 \mathrm{Nb}$ & C2 & t11656 & - & - \\
\hline T139N & C2 & t11656 & + & V \\
\hline T145N & C2 & t11656 & + & V \\
\hline T022N & C2 & t645 & - & - \\
\hline T041Na & C2 & t645 & - & - \\
\hline T099Nb & C2 & t645 & + & V \\
\hline T063N & C3 & t355 & + & V \\
\hline T053N & D1 & t1376 & + & IVC \\
\hline T055N & D1 & t1376 & + & V \\
\hline T039Na & E1 & t318 & + & IVC \\
\hline T041Nb & E2 & t645 & + & V \\
\hline T025N & E3 & t2393 & + & IVC \\
\hline T030Nb & F1 & t064 & + & V \\
\hline T158Nb & G1 & $\mathrm{t} 127$ & - & - \\
\hline T087 & $\mathrm{H} 1$ & t064 & + & V \\
\hline $\mathrm{T} 155 \mathrm{Nd}$ & $\mathrm{H} 2$ & t509 & - & - \\
\hline T097Nb & 11 & t002 & - & - \\
\hline
\end{tabular}

ID identification number of the isolate, + positive on PCR amplification, - negative on PCR amplification, NT not typable 
Table 2 PFGE profiles, mecA, and SCCmec types of PVL negative isolates

\begin{tabular}{|c|c|c|c|c|}
\hline Isolate ID & Pulsotype & Spa type & mecA & sccmec \\
\hline $\mathrm{T} 117 \mathrm{Nb}$ & E1 & t786 & - & - \\
\hline $\mathrm{T} 119 \mathrm{Na}$ & E1 & t786 & - & - \\
\hline T092Na & E2 & $\mathrm{t} 186$ & - & - \\
\hline T058Nb & E4 & t7662 & - & - \\
\hline T061Nd & L1 & $\mathrm{t} 1236$ & + & V \\
\hline T061Nb & L1 & $\mathrm{t} 1236$ & + & V \\
\hline T059Na & L2 & Unknown & + & V \\
\hline T059Nb & L3 & Unknown & + & V \\
\hline T099Na & L3 & Unknown & + & V \\
\hline $\mathrm{T} 021 \mathrm{Nd}$ & $\llcorner 4$ & Unknown & + & V \\
\hline T032NC & $\mathrm{F} 1$ & t064 & - & - \\
\hline $\mathrm{T} 131 \mathrm{Nb}$ & $\mathrm{F} 1$ & t064 & - & - \\
\hline T032Nb & $\mathrm{F} 1$ & T064 & - & - \\
\hline T061NC & N1 & $\mathrm{t} 2771$ & + & V \\
\hline T074NC & N1 & $\mathrm{t} 2771$ & + & V \\
\hline T074Nb & N1 & $\mathrm{t} 2771$ & + & V \\
\hline T029Nb & $\mathrm{H} 1$ & t002 & - & - \\
\hline T101Nf & $\mathrm{H} 1$ & t002 & + & V \\
\hline T076N & G1 & t5739 & + & V \\
\hline $\mathrm{T} 128 \mathrm{Nd}$ & G1 & $\mathrm{t} 2680$ & + & V \\
\hline T018Nb & $\mathrm{G} 2$ & t616 & + & V \\
\hline T092Nb & P1 & $\mathrm{t} 4353$ & + & V \\
\hline $\mathrm{T} 102 \mathrm{Nb}$ & P2 & $\mathrm{t} 4353$ & - & - \\
\hline $\mathrm{T} 127 \mathrm{Na}$ & Q1 & Unknown & - & - \\
\hline T137Ng & Q1 & t064 & - & - \\
\hline $\mathrm{T} 110 \mathrm{Nb}$ & R1 & $\mathrm{t} 4523$ & - & - \\
\hline $\mathrm{T} 111 \mathrm{Na}$ & R2 & t5187 & + & V \\
\hline T027Nb & R3 & t5187 & + & V \\
\hline T004Nb & Unique & t3772 & + & V \\
\hline T033Nb & Unique & Unknown & + & V \\
\hline T005Nb & Unique & t951 & + & V \\
\hline $\mathrm{T} 114 \mathrm{Ng}$ & Unique & Unknown & - & - \\
\hline $\mathrm{T} 151 \mathrm{Nb}$ & Unique & t5739 & + & V \\
\hline $\mathrm{T} 115 \mathrm{Na}$ & Unique & Unknown & + & $\mathrm{IVa}$ \\
\hline $\mathrm{T} 120 \mathrm{~N}$ & Unique & t5187 & + & V \\
\hline $\mathrm{T} 126 \mathrm{~N}$ & Unique & NT & + & $\mathrm{IVa}$ \\
\hline $\mathrm{T} 104 \mathrm{Nb}$ & Unique & Unknown & - & - \\
\hline
\end{tabular}

ID identification number of the isolate

positive isolates were SCCmec type $\mathrm{V}$, while the other seven were all SCCmec IVc. Among the PVL negative isolates, 21 of the 23 mecA positive isolates were SCCmec type V, while the other two were type IVa.
Molecular epidemiology of MRSA PVL positive and PVL negative strains

PFGE profiles of PVL positive and negative isolates were analyzed separately to understand any difference in transmission within the two groups. Among the PVL positive isolates, $21 / 36(58.3 \%)$ strains were found in four clusters (A1, B1, C2, D1, Table 1); while in PVL negative isolates, $18 / 37$ (48.6\%) were found in eight clusters (E1, L1, L3, F1, N1, H1, G1, Q1, Table 2). Some family members carried identical strains. In order to relate the genotypes of the isolates in this study to global epidemiology of S. aureus, we performed Spa typing of the PVL positive isolates. Only two of the 36 isolates could not be typed by this technique, but they belonged to the same pulsotype (A1). In all, there were $13 \mathrm{Spa}$ types among the 34 typable PVL positive $S$. aureus isolates. The most prevalent Spa types were $\mathrm{t} 318$ comprising of $26.5 \%(n=9)$, of which seven isolates carried the mecA gene; and $\mathrm{t} 645(20.6 \%, n=7)$. The other common Spa types were and $\mathrm{t} 11656(8.8 \%, n=3)$ and $\mathrm{t} 127(n=3)$. The other Spa types, their frequencies and PFGE profiles can be seen in Table 1 .

\section{Discussion}

Knowledge of the epidemiology of bacterial infections is very important for appropriate decision-making in the treatment of arising infections. At a community level, it is also important to curb the spread of infection, including multidrug resistant strains. To our knowledge, this is the first investigation of Panton-Valentine Leukocidin-Positive CA-MRSA in asymptomatic seminomadic pastoralist communities in the East African region. The main findings of the study are a high prevalence of MRSA and PVL-positive isolates with a predominant spa type (t318).

This study isolated 132 Staphylococci isolates from the nares of 253 participants, of which 73 were coagulase positive S. aureus (carriage rate of 29\%). The 73 isolates of $S$. aureus in our study were obtained from 48 male and 25 female participants, with an average age of 13 years, with 56/73 (76. 7\%) of the participants being between 7 and 15 years old. This is similar to observations elsewhere that CA-MRSA infections tend to occur in previously healthy younger patients [21, 32, 33]. Our finding is of public health importance because this school-going age group has potential of disseminating the strains far and wide in the communities. The carriage rate in our study is more than double that in a study on milk men in and around Kampala city, Uganda, where only 11 Staphylococci were isolated from 31 individuals, of which only $4 / 31$ (13\%) were $S$. aureus [26]. Our finding, however, is in agreement with statistics from literature suggesting that between 25 to $35 \%$ of 
healthy individuals are asymptomatically colonized with $S$. aureus in the nostrils [1, 21, 34, 35].

In the current study, the proportion of $S$. aureus isolates carrying the mecA gene, hence MRSA, was 48/73 $(65.8 \%)$. This is generally high in comparison to community studies elsewhere. In the urban and peri-urban Kampala, the four isolates from milk men were all MSSA. In a study of indigenous remote African Babongo pygmies living in Waka National Parc, Central Gabon, all $34 S$. aureus isolates were susceptible to Oxacillin/ Methicillin, and did not amplify for the mecA gene by PCR. The authors hypothesized that the result could be due to limited use of antibiotics in that population. Studies in North America and Australia, however, have shown that native and indigenous populations have been associated with a high risk of colonization and infection with CA-MRSA which may be related to many of these groups being disadvantaged, due to their association with low socio-economic status, crowded living conditions and frequent use of antibiotics [36, 37]. There have been reports of absolute resistance to penicillin and high percentage resistance to other antibiotics in milk from similar settings in central Uganda, hence risk of spread to humans through the food chain [27]. In our study community there is frequent usage, by farmers, of veterinary antibiotics to treat nearly all ailments in their livestock, due to poor outreach services by the veterinary department. It is therefore more likely that constant contact with antibiotics for animal use, as well as consumption of raw milk and its products without observing drug withdrawal periods, as is the culture in this setting, are limiting future options for the management of multidrug resistant microorganisms in both humans and animals in pastoral communities of Uganda. Among the 48 isolates carrying the mecA gene, 39 (81.3\%) were type $\mathrm{V}$, the other being type IV or its subtypes (Tables 1 and 2). Type IV and V SCCmec elements have strongly been associated with stains causing MRSA infections in persons with no history of hospitalization, hence thought to be more related to CA-MRSA [38]. Furthermore, it has been shown that children may be at a higher risk of infection with SCCmec types IV and V, as well as PVL carrying strains, compared to adults [38, 39]. SCCmec type $\mathrm{V}$, which comprised of $81.3 \%$ of the mecA positive strains in our study, is known to be rare in Europe and the United States [33], and only recently seen in Greece [40]. Because SCCmec type IV and V are known to be small and highly mobile elements, their dissemination in a community population may be most commonly by transfers of strains from carriers to other individuals or from MRSA strains to Methicillin Sensitive Staphylococcus aureus (MSSA strains), or even from coagulase-negative staphylococci strain to an MSSA strain [41]. However, a recent study on patients with surgical site infections (SSI) at the National Referral hospital in Mulago, Kampala, showed that SCCmec type V was the most predominant type [22], suggesting the presence of mixed CA-MRSA and HA-MRSA genotypes in hospital settings in Uganda.

A further characterization of the 36 isolates carrying the PVL gene in this study was done. SCCmecIV and PVL are known to be molecular markers associated with the emergence of CA-MRSA worldwide [10]. The proportion of strains carrying both the PVL and mecA genes was $25 / 36(69.4 \%)$, while the $m e c A$ gene was detected in 23/37 (62.2\%) of the isolates without the PVL gene. While there was no significant difference in $\operatorname{mec} A$ carriage, PFGE profiles for both PVL positive and negative isolates show that there were bigger clusters in PVL positive strains (Table 1) compared to PVL negative strains (Table 2). In fact, 18/37 (48.6\%) of the PVL negative isolates were in clusters (Table 1) compared to 21/36 (58.3\%) of PVL positive isolates, with the largest (B1) comprising of eight isolates (Table 1). These results suggest that PVL positive isolates in the study were more likely to be involved in chains of transmission compared to the PVL negative isolates. There has been recent evidence of familial spread of PVL carrying MSSA strains in Israel [42] and MRSA strains in Italy [43], while a previous study in Greece revealed that a unique clone of PVL-positive MRSA had spread in both the community and hospital settings, and was replacing older clonal types [44]. In Central Gabon, Africa, PVLencoding genes were detected in $55.9 \%$ of study isolates, with authors concluding that the pygmies in that study faced a risk of developing necrotizing infections, due to the virulence characteristic of the PVL. The finding of a high proportion of isolates carrying both the PVL and mecA genes in our study may have considerable implications on future strategies for infection control in these underprivileged communities.

Among the PVL positive isolates, there was a predominant circulating Spa type, t318, comprising of nine of the 34 (26.5\%) typable isolates. This is the first time the Spa type has been identified in a Ugandan setting. Moreover, seven strains (77.8\%) of this Spa type carried the mecA gene, pointing to the presence of a potentially virulent methicillin resistant strain circulating in the community. This strain has been found to be pandemic, and mostly PVL positive, also denoted ST30 by multilocus sequence typing. It has recently been mapped to have originated from Australia and disseminated to Brazil, United States, South Africa and Western Europe [3]. However, it is not related to the USA300, belonging to ST8 and leading cause of CA-MRSA in the USA. It has been revealed that PVL is most frequent in pandemic CA-MRSA strains and certain MSSA lineages, including ST30, appear to be a reservoir of CA-MRSA [6]. Surprisingly, ST30 has also been isolated from Babongo pygmies of Gabon in Africa, who are known 
to have been separated from other humans over millennia ago [21]. In a study of MRSA in five African cities, only one strain of this type was isolated from Antananarivo, and none from Cassablanca (Moroco), Niamey (Niger), Dakar (Senegal) and Yaoundé (Cameroon). While SCCmec type $\mathrm{V}$ strains have been isolated from hospital settings in Uganda, none were Spa type t318 [22]. However, Spa type t645, the second most frequent type in our collection (20.6\%), also common in Western Europe and the Middle East (http://spaserver.ridom.de), was found to be the most frequent type isolated from SSI at Mulago National referral hospital [22], supporting the notion that there is a changing epidemiology reflected by community associated SCCmec genotypes being now more associated with hospital infections as observed elsewhere [23, 45]. However, it is noteworthy that some spa types of PVL+ S. aureus in the present study (t186, t729 and t355) have been previously identified in studies from Africa, and they all share the MLST type ST88 [46].

\section{Conclusion}

The main findings of this study are a high prevalence of CA-MRSA, and PVL-positive isolates with a predominant spa type in a rural setting in Uganda. This has implication on future strategies for infection control in these underprivileged communities because of possibility of limited treatment options. Antimicrobial stewardship programs may be necessary in Uganda so as to create awareness and avert possible emergence multidrug resistant microorganisms in the near future.

\section{Acknowledgments}

The authors wish to thank the households that participated in the study.

\section{Funding}

BBA was supported by a Marie Curie Fellowship (MARIE CURIE - COFUND) project No. 267264).

\section{Availability of data and materials}

All data supporting the conclusions of this article are included within the article.

\section{Authors' contributions}

BBA collected samples and data, participated in performing all the laboratory analyses and wrote the first draft of the manuscript; RB participated in analyzing and interpreting PFGE data and critical revision of the manuscript; AT participated in performing PFGE; DMC supervised the study and critically revised the manuscript. All authors read and approved the final manuscript.

\section{Competing interests}

The authors declare that they have no competing interests.

\section{Consent for publication}

Not applicable.

\section{Ethics approval and consent to participate}

The study protocol was approved by the Institutional Review Board of the School of Biomedical Sciences, Makerere University College of Health Sciences; and by the Uganda National Council for Science and Technology. The study objective was explained in the local language and written informed consent obtained from each participant before taking a sample. For participating minors within recruited households, both assent from the minors as well as consent from the parents were sought before a swab was taken.

\section{Author details}

${ }^{1}$ Emerging Bacterial Pathogens Unit, IRCCS San Raffaele Scientific Institute, Via Olgettina 58, Milano, Italy. ${ }^{2}$ Universita Vita-Salute San Raffaele, Via Olgettina 58, Milano, Italy. ${ }^{3}$ Department of Medical Microbiology, Makerere University College of Health Sciences, P. O. Box 7072, Kampala, Uganda.

Received: 1 September 2016 Accepted: 14 December 2016

Published online: 05 January 2017

\section{References}

1. Gorwitz RJ, Kruszon-Moran D, McAllister SK, McQuillan G, McDougal LK, et al. Changes in the prevalence of nasal colonization with Staphylococcus aureus in the United States, 2001-2004. J Infect Dis. 2008;197:1226-34.

2. von Eiff C, Becker K, Machka K, Stammer H, Peters G, et al. Nasal carriage as a source of Staphylococcus aureus bacteremia. N Engl J Med. 2001;344:11-6.

3. DeLeo FR, Otto M, Kreiswirth BN, Chambers HF. Community-associated meticillin-resistant Staphylococcus aureus. Lancet. 2010;375:1557-68.

4. Herold BC, Immergluck LC, Maranan MC, Lauderdale DS, Gaskin RE, et al. Community-acquired methicillin-resistant Staphylococcus aureus in children with no identified predisposing risk. JAMA. 1998;279:593-8.

5. Loffler B, Hussain M, Grundmeier M, Bruck M, Holzinger D, et al. Staphylococcus aureus panton-valentine leukocidin is a very potent cytotoxic factor for human neutrophils. PLoS Pathog. 2010;6:e1000715.

6. Rasigade JP, Laurent F, Lina G, Meugnier H, Bes M, et al. Global distribution and evolution of Panton-Valentine leukocidin-positive methicillin-susceptible Staphylococcus aureus, 1981-2007. J Infect Dis. 2010;201:1589-97.

7. Ito T, Okuma K, Ma XX, Yuzawa H, Hiramatsu K. Insights on antibiotic resistance of Staphylococcus aureus from its whole genome: genomic island SCC. Drug Resist Updat. 2003;6:41-52.

8. Ito T, Ma XX, Takeuchi F, Okuma K, Yuzawa H, et al. Novel type V staphylococcal cassette chromosome mec driven by a novel cassette chromosome recombinase, ccrC. Antimicrob Agents Chemother. 2004;48: 2637-51.

9. Daum RS, Ito T, Hiramatsu K, Hussain F, Mongkolrattanothai K, et al. A novel methicillin-resistance cassette in community-acquired methicillin-resistant Staphylococcus aureus isolates of diverse genetic backgrounds. J Infect Dis. 2002;186:1344-7.

10. Vandenesch F, Naimi T, Enright MC, Lina G, Nimmo GR, et al. Communityacquired methicillin-resistant Staphylococcus aureus carrying Panton-Valentine leukocidin genes: worldwide emergence. Emerg Infect Dis. 2003;9:978-84.

11. Shukla SK, Stemper ME, Ramaswamy SV, Conradt JM, Reich R, et al. Molecular characteristics of nosocomial and Native American communityassociated methicillin-resistant Staphylococcus aureus clones from rural Wisconsin. J Clin Microbiol. 2004;42:3752-7.

12. Tenover FC, Arbeit RD, Goering RV, Mickelsen PA, Murray BE, et al. Interpreting chromosomal DNA restriction patterns produced by pulsedfield gel electrophoresis: criteria for bacterial strain typing. J Clin Microbiol. 1995:33:2233-9.

13. Frenay HM, Bunschoten AE, Schouls LM, van Leeuwen WJ, VandenbrouckeGrauls CM, et al. Molecular typing of methicillin-resistant Staphylococcus aureus on the basis of protein A gene polymorphism. Eur J Clin Microbiol Infect Dis. 1996;15:60-4.

14. Koreen L, Ramaswamy SV, Graviss EA, Naidich S, Musser JM, et al. spa typing method for discriminating among Staphylococcus aureus isolates: implications for use of a single marker to detect genetic micro- and macrovariation. J Clin Microbiol. 2004;42:792-9.

15. Shore AC, Coleman DC. Staphylococcal cassette chromosome mec: recent advances and new insights. Int J Med Microbiol. 2013;303:350-9.

16. Zhang K, McClure JA, Elsayed S, Louie T, Conly JM. Novel multiplex PCR assay for characterization and concomitant subtyping of staphylococcal cassette chromosome mec types I to V in methicillin-resistant Staphylococcus aureus. J Clin Microbiol. 2005;43:5026-33.

17. Ruimy R, Maiga A, Armand-Lefevre L, Maiga I, Diallo A, et al. The carriage population of Staphylococcus aureus from Mali is composed of a combination of pandemic clones and the divergent Panton-Valentine leukocidin-positive genotype ST152. J Bacteriol. 2008;190:3962-8.

18. Ghebremedhin B, Olugbosi MO, Raji AM, Layer F, Bakare RA, et al. Emergence of a community-associated methicillin-resistant Staphylococcus aureus strain with a unique resistance profile in Southwest Nigeria. J Clin Microbiol. 2009;47:2975-80. 
19. Ramdani-Bouguessa N, Bes M, Meugnier H, Forey F, Reverdy ME, et al. Detection of methicillin-resistant Staphylococcus aureus strains resistant to multiple antibiotics and carrying the Panton-Valentine leukocidin genes in an Algiers hospital. Antimicrob Agents Chemother. 2006:50:1083-5.

20. Enany S, Yaoita E, Yoshida Y, Enany M, Yamamoto T. Molecular characterization of Panton-Valentine leukocidin-positive communityacquired methicillin-resistant Staphylococcus aureus isolates in Egypt. Microbiol Res. 2010;165:152-62

21. Schaumburg F, Kock R, Friedrich AW, Soulanoudjingar S, Ngoa UA, et al. Population structure of Staphylococcus aureus from remote African Babongo Pygmies. PLoS Negl Trop Dis. 2011;5:e1150.

22. Seni J, Bwanga F, Najjuka CF, Makobore P, Okee M, et al. Molecular characterization of Staphylococcus aureus from patients with surgical site infections at Mulago Hospital in Kampala, Uganda. PLoS One. 2013;8:e66153.

23. Kateete DP, Namazzi S, Okee M, Okeng A, Baluku H, et al. High prevalence of methicillin resistant Staphylococcus aureus in the surgical units of Mulago hospital in Kampala, Uganda. BMC Res Notes. 2011;4:326.

24. Ojulong J, Mwambu TP, Joloba M, Bwanga F, Kaddu-Mulindwa DH. Relative prevalence of methicilline resistant Staphylococcus aureus and its susceptibility pattern in Mulago Hospital, Kampala, Uganda. Tanzan J Health Res. 2009;11:149-53.

25. Iramiot S, Bwanga F, Itabangi $H$, Nakaye $M$, Bashir $M$, et al. Prevalence and antibiotic susceptibility patterns of clinical isolates of Methicillin-resistant staphylococcus aureus in a tertiary care Hospital in Western Uganda. British Microbiol Res J. 2014;4:1168-77.

26. Kateete DP, Kabugo U, Baluku H, Nyakarahuka L, Kyobe S, et al. Prevalence and antimicrobial susceptibility patterns of bacteria from milkmen and cows with clinical mastitis in and around Kampala, Uganda. PLoS One. 2013;8:e63413.

27. Kasozi Kl, Tingiira JB, Vudriko P. High prevalence of subclinical mastitis and multidrug resistant staphylococcus aureus are a threat to dairy cattle production in Kiboga District (Uganda). Open J Vet Med. 2014;4:35-43.

28. Cheesbrough M. District Laboratory Practice in Tropical Countries, Part 2. 2nd ed. 2005. p. 62-70. 132-143, 157-234.

29. Lina G, Piemont Y, Godail-Gamot F, Bes M, Peter MO, et al. Involvement of Panton-Valentine leukocidin-producing Staphylococcus aureus in primary skin infections and pneumonia. Clin Infect Dis. 1999:29:1128-32.

30. Baldan R, Tassan Din C, Semeraro G, Costa C, Cichero P, et al. Severe community-onset infections in healthy individuals caused by communityacquired MRSA in an Italian teaching hospital, 2006-2008. J Hosp Infect. 2009;72:271-3.

31. Mellmann A, Friedrich AW, Rosenkotter N, Rothganger J, Karch $\mathrm{H}$, et al. Automated DNA sequence-based early warning system for the detection of methicillin-resistant Staphylococcus aureus outbreaks. PLoS Med. 2006;3:e33.

32. Naimi TS, LeDell KH, Como-Sabetti K, Borchardt SM, Boxrud DJ, et al. Comparison of community- and health care-associated methicillin-resistant Staphylococcus aureus infection. JAMA. 2003;290:2976-84.

33. David MZ, Daum RS. Community-associated methicillin-resistant Staphylococcus aureus: epidemiology and clinical consequences of an emerging epidemic. Clin Microbiol Rev. 2010;23:616-87.

34. Wertheim HF, Melles DC, Vos MC, van Leeuwen W, van Belkum A, et al. The role of nasal carriage in Staphylococcus aureus infections. Lancet Infect Dis. 2005;5:751-62.

35. McNally LM, Jeena PM, Gajee K, Sturm AW, Tomkins AM, et al. Lack of association between the nasopharyngeal carriage of Streptococcus pneumoniae and Staphylococcus aureus in HIV-1-infected South African children. J Infect Dis. 2006;194:385-90.

36. Tong SY, McDonald MI, Holt DC, Currie BJ. Global implications of the emergence of community-associated methicillin-resistant Staphylococcus aureus in Indigenous populations. Clin Infect Dis. 2008;46:1871-8.

37. Vlack S, Cox L, Peleg AY, Canuto C, Stewart C, et al. Carriage of methicillinresistant Staphylococcus aureus in a Queensland Indigenous community. Med J Aust. 2006:184:556-9.

38. David MZ, Glikman D, Crawford SE, Peng J, King KJ, et al. What is community-associated methicillin-resistant Staphylococcus aureus? J Infect Dis. 2008;197:1235-43.

39. David MZ, Crawford SE, Boyle-Vavra S, Hostetler MA, Kim DC, et al Contrasting pediatric and adult methicillin-resistant Staphylococcus aureus isolates. Emerg Infect Dis. 2006;12:631-7.
40. Chini V, Petinaki E, Meugnier H, Foka A, Bes M, et al. Emergence of a new clone carrying Panton-Valentine leukocidin genes and staphylococcal cassette chromosome mec type $V$ among methicillin-resistant Staphylococcus aureus in Greece. Scand J Infect Dis. 2008;40:368-72.

41. Hallin M, Denis O, Deplano A, De Mendonca R, De Ryck R, et al. Genetic relatedness between methicillin-susceptible and methicillin-resistant Staphylococcus aureus: results of a national survey. J Antimicrob Chemother. 2007;59:465-72.

42. Adler A, Temper V, Block CS, Abramson N, Moses AE. Panton-Valentine leukocidin-producing Staphylococcus aureus. Emerg Infect Dis. 2006;12: 1789-90.

43. Cocchi P, Taccetti G, Montagnani C, Campana S, Galli L, et al. Evidence of transmission of a Panton-Valentine leukocidin-positive community-acquired methicillin-resistant Staphylococcus aureus clone: a family affair. Clin Microbiol Infect. 2013;19:1158-62.

44. Chini V, Petinaki E, Foka A, Paratiras S, Dimitracopoulos G, et al. Spread of Staphylococcus aureus clinical isolates carrying Panton-Valentine leukocidin genes during a 3-year period in Greece. Clin Microbiol Infect. 2006;12:29-34.

45. Shittu AO, Okon K, Adesida S, Oyedara O, Witte W, et al. Antibiotic resistance and molecular epidemiology of Staphylococcus aureus in Nigeria. BMC Microbiol. 2011;11:92

46. Schaumburg F, Pauly M, Anoh E, Mossoun A, Wiersma L, et al. Staphylococcus aureus complex from animals and humans in three remote African regions. Clin Microbiol Infect. 2015;21(345):e341-8.

\section{Submit your next manuscript to BioMed Central and we will help you at every step:}

- We accept pre-submission inquiries

- Our selector tool helps you to find the most relevant journal

- We provide round the clock customer support

- Convenient online submission

- Thorough peer review

- Inclusion in PubMed and all major indexing services

- Maximum visibility for your research

Submit your manuscript at www.biomedcentral.com/submit
C) Biomed Central 